\title{
ANÁLISE DO DISCURSO APLICADA EM CHARGES E A MATEMÁTICA ${ }^{1}$
}

\author{
Vanessa Isabel Cataneo ${ }^{2}$ \\ Centro Universitário Barriga Verde - Unibave. Santa Catarina, Brasil.
}

\begin{abstract}
Resumo: O presente artigo apresenta o estudo sobre o gênero discursivo aplicado em charges que envolvem a matemática. $\mathrm{O}$ estudo encontra-se fundamentado em uma pesquisa bibliográfica e em análises de textos sobe à luz da teoria da Análise do Discurso (AD) da linha Francesa. Por meio da pesquisa bibliográfica, se realizou uma compilação crítica dos teóricos que tratam da Análise do Discurso, com o objetivo de estudar qual o papel do diálogo no discurso. Assim como, apresentar quais são as condições de gênero charge, portador de elementos de natureza irônica e humorística. Para tanto, se fez um levantamento de charges que envolvem situações matemáticas e que se encontram divulgadas na internet. Palavras-chave: Discurso; matemática; charge.
\end{abstract}

\section{ANÁLISIS DEL DISCURSO APLICABLE EN CARICATURAS Y LA MATEMÁTICA}

Resumen: El presente artículo presenta el estudio a respecto del género discursivo aplicado en las caricaturas que involucran a las matemáticas. El estudio se encuentra fundamentado en una investigación bibliográfica y en análisis de textos sube a la luz de la teoría del Análisis del Discurso (AD) de la línea Francesa. A través de la investigación bibliográfica, se realizó una compilación crítica de los teóricos que tratan del Análisis del Discurso, con el objetivo de estudiar cuál es el papel del diálogo en el discurso. Así como, presentar cuáles son las condiciones del género de las caricaturas, portador de elementos de naturaleza irónica y humorística. Para ello, se hizo un levantamiento de caricaturas que involucran situaciones matemáticas y que se encuentran divulgadas en internet.

Palabras clave: Discurso; Matemática; Caricaturas.

\section{ANALYSIS OF THE SPEECH APPLIED IN CHARGES AND MATHEMATICS}

\begin{abstract}
This article presents the study about the discursive genre applied in cartoons involving mathematics. The study is based on a bibliographical research and analysis of texts based on the Discourse Analysis (DA) theory of the French line. Through the bibliographical research, a critical compilation of the theorists dealing with Discourse Analysis was carried out, in order to study the role of dialogue in discourse. Just like, present what are the conditions of genre charge, bearer of elements of

\footnotetext{
${ }^{1}$ Este artigo é resultado do estudo da disciplina de Análise do Discurso cursada no Programa de Doutorado em Ciências da Linguagem.

${ }^{2}$ Doutoranda do Programa de Pós-Graduação em Ciências da Linguagem - Unisul. E-mail: vanessaisacataneo@hotmail.com. Professora de rede pública estadual de Santa Catarina e Professora na Graduação do Centro Universitário Barriga Verde - Unibave.
} 
ironic and humorous nature. For that, a survey of cartoons involving mathematical situations was published and found on the Internet.

Keywords: Speech; Mathematics; Charge.

\section{Introdução}

As charges são um tipo de gênero da linguagem, e apresentam em sua composição diferentes tipos de discurso, assim à teoria Análise do Discurso proveniente da linha Francesa, auxilia na busca pela compreensão do sentido do texto presente em charges. Neste estudo em especial, a análise do discurso e do diálogo será realizado em charges que fazem menção ao ensino e aprendizagem da matemática. Conforme Orlandi (1999) " $\mathrm{Na}$ análise de discurso, procura-se compreender a língua fazendo sentido, enquanto trabalho simbólico, parte do trabalho social geral, constitutivo do homem e da sua história" (p. 15).

A natureza de todo sistema de comunicação, de toda linguagem é eminentemente ideológica e a charge é uma delas. Para Bakhtin (1999) todo signo é ideológico e possui sua materialidade que se constrói no ambiente social da comunicação, por meio da interação verbal. Assim o autor defende que:

"Um produto ideológico faz parte de uma realidade (natural ou social) como todo corpo físico instrumento de produção ou produto de consumo; mas ao contrário destes ele também reflete e retrata uma outra realidade, que lhe é exterior. Tudo que é ideológico possui um significado e remete a algo situado fora de si mesmo. Em outros termos, tudo que é ideológico é um signo. Sem signos não existe ideologia. (...). A existência do signo nada mais é do que a materialização de uma comunicação. É nisso que consiste a natureza de todos os signos ideológicos" (Bakhtin, 1999, p. 31-36).

A charge é um gênero que transita de forma harmoniosa entre as linguagens verbal e não verbal. Faz o uso de desenhos para se referir a fatos, com o propósito de denunciar, ironizar, criticar e satirizar. Ela evidencia que o sentido é construído no movimento entre o dito e não dito, de modo que, o leitor pode desconstruir e construir sentido gerando nesse processo inferências a partir da relação entre a leitura da imagem e o evento que originou a charge em sua historicidade ideológica e social.

As diferentes esferas de uso da linguagem geram os gêneros discursivos a partir dos quais se organizam os textos. Bakhtin (1997) classifica os gêneros discursivos em primários e secundários e enquadra a charge como gênero secundário. Visto que, a charge aparece em circunstâncias de uma comunicação cultural mais complexa e relativamente mais evoluída. Assim para compreender o discurso de uma charge o leitor necessita identificar os personagens os fatos o contexto social, histórico e político caso exista. Bem como, as circunstâncias, os elementos linguísticos (se houver) e as possíveis intenções do chargista.

Neste contexto Marcuschi (2008) enfatiza que:

"Cada gênero textual tem um propósito bastante claro que o determina e lhe dá uma esfera de circulação. [...] todos os gêneros tem uma forma e uma função, bem como um estilo e um conteúdo, mas sua determinação se dá basicamente pela função e não pela forma" (p. 150). 
Assim, a leitura e compreensão deste gênero provocam efeitos de sentido diferenciados dependendo do conhecimento de mundo do leitor. O discurso será o lugar em que se pode observar tal prática. Nas palavras de Orlandi (1999)

"A análise de discurso visa a compreensão de como um objeto simbólico ${ }^{3}$ produz sentidos, como ele está investido de significância para e por sujeitos. Essa compreensão, por sua vez, implica explicar como o texto organiza os gestos de interpretação que relacionam sujeito e sentido" (p. 26).

A Análise do Discurso teve origem na década de 1960 do século XX, essa teoria provoca o reconhecimento da dualidade constitutiva da linguagem, originando mudanças nos estudos linguísticos até então realizados. Para muitos estudiosos é com o lançamento do livro Análise Automática do Discurso em 1969 por Michel Pêcheux que tem inicio a disciplina Análise do Discurso. Pêcheux tomou o discurso como objeto de análise, diferenciando-o da língua e da fala e sim considerando que o discurso implica uma exterioridade à língua que se encontra presente em aspectos sociais e ideológicos nas palavras quando pronunciadas.

Conforme Orlandi (1999), o discurso não é apenas uma transmissão de informação, pois pelas relações de linguagem ocorrem as relações de sujeito e de sentidos com efeitos variados. "Daí a definição de discurso: o discurso é efeito de sentidos entre locutores" (p. 21).

Nesta perspectiva Orlandi (1999) define:

"Nos estudos discursivos, não se separam forma e conteúdo e procurase compreender a língua não só como uma estrutura, mas, sobretudo como acontecimento. Reunindo estrutura e acontecimento a forma material é vista como o acontecimento do significante (língua) em um sujeito afetado pela história" (p. 19).

Todavia, esse campo de estudos se constituiu a partir de três domínios disciplinares a Linguística para explicar os processos da enunciação; o Marxismo para explicar os fenômenos das formações sociais e a Psicanálise para explicar a subjetividade e a relação do sujeito com o simbólico. Assim, a Análise do Discurso rompeu com os postulados da linguística clássica, pois sua proposta é o estudo linguístico das condições de produção de um enunciado. De modo que o discurso se encontra no resultado da intersecção do linguístico, do histórico e do ideológico. (Orlandi, 1999).

$\mathrm{Na}$ figura a seguir, exemplificamos por meio da construção de um diagrama a ideia dessa intersecção entre os três domínios disciplinares para a investigação de um novo objeto de estudo: o discurso.

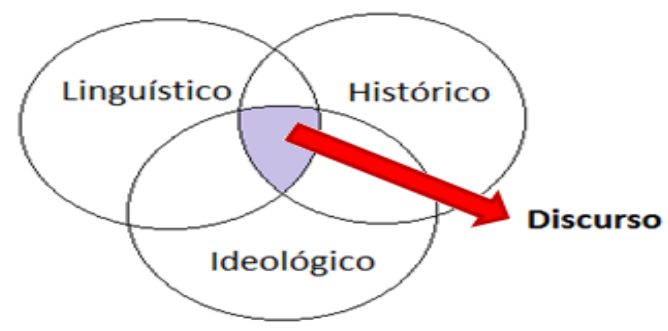

Figura 1. Análise do Discurso

Note: Fonte: Construção da autora (2016).

\footnotetext{
${ }^{3}$ Objeto simbólico (enunciado, texto, pintura, música etc). (Orlandi, 1999 p. 26).
} 
Assim na Análise do Discurso a língua não é um sistema abstrato, mas sim possui significado, qual varia conforme o homem fala, nisso considera-se a história de vida desse homem enquanto sujeito e quanto membro de uma determinada configuração de sociedade. Dessa forma, para Orlandi (1999) o sujeito de linguagem não possui autonomia, visto que é afetado pelo real da língua e pelo real da história, não possuindo o controle de como elas o afetam, isto é, as palavras que fazem parte do nosso dia a dia, chegam até nos carregadas de sentidos que não sabemos como se constituíram, porém significam em nós e para nós.

Neste contexto Ribeiro (1997) define:

"Para a AD, a ênfase está no assujeitamento do sujeito frente às estruturas de funcionamento da ideologia. Ou seja, o sujeito tem a ilusão de que é senhor do seu discurso, e não apenas um efeito, um produto deste. Logo, para a $\mathrm{AD}$, a autonomia do sujeito é uma ilusão" (p. 30).

Portanto, é através do condicionamento do sujeito à formação ideológica e à formação discursiva que o enunciador constrói representações fundamentais de seu discurso para o seu interlocutor, assim como também ele imagina o que seu interlocutor irá pensar a respeito dele e de seu discurso. Isso provoca o jogo de imagens, que faz parte da teoria de Pêcheux.

\section{Discurso e a realidade}

No discurso as palavras recebem seus sentidos de formações discursivas no processo de relação, que é determinado pelo interdiscurso, isto é, a memória, sendo que a interpretação acontece entre a memória institucional (o arquivo) e os efeitos de memória (interdiscurso), o que pode estabilizar ou deslocar sentidos. Nesse caso a ideologia $^{4}$ não é ocultação da relação e sim função da relação necessária entre linguagem e mundo.

Então Orlandi (1999) ressalta que:

"Para pensarmos a ideologia, nessa perspectiva, pensamos a interpretação. Para que a língua faça sentido, é preciso que a história intervenha, pelo equivoco, pela opacidade, pela espessura material do significante. Daí resulta que a interpretação é necessariamente regulada em suas possibilidades, em suas condições" (p. 47).

A Análise do Discurso busca o real sentido em sua materialidade linguística e histórica, portanto cabe ressaltar que, a ideologia não se aprende e o inconsciente não se controla com o saber, Pêcheux dirá que a própria língua funciona ideologicamente, todo enunciado oferece possibilidade de interpretação e é suscetível de ser e tornar-se outro. "Esse lugar do outro enunciado é o lugar da interpretação, manifestação do inconsciente e da ideologia na produção dos sentidos e na constituição dos sujeitos". (Orlandi, 1999, p. 59).

Assim, o analista de discurso necessita não apenas trabalhar o real da língua, mas também é indispensável e fundamental para o seu campo de ação que trabalhe com o real da história. Visto que para Orlandi (2012), o material linguístico enquanto capacidade abstrata define-se como sistema. Este sistema na Análise do Discurso se trata de um sistema significante, qual esta exposto a falhas, pois para cumprir o seu designo de significar é afetado pelo real da história.

Neste sentido, não interessa no primeiro momento a Análise do Discurso os atos que a linguagem realiza, mas, a realidade que se constitui nos sentidos que o sujeito

\footnotetext{
${ }^{4}$ Segundo Orlandi (1999, p. 48) “A ideologia, por sua vez, nesse modo de a conhecer, não é vista como conjunto de representações, como visão de mundo ou como ocultação da realidade. Não há aliás realidade sem ideologia. Enquanto prática significante, a ideologia aparece como efeito da relação necessária do sujeito com a língua e a com a história para que haja sentido". A Ideologia é a condição para a constituição do sujeito e dos sentidos.
} 
pratica. Logo, o sujeito ao falar se significa e significa o próprio mundo, sendo então a linguagem nesta perspectiva uma prática. Nas palavras de Orlandi (2012), a linguagem é uma prática "não no sentido de realizar atos, mas porque pratica sentidos, ação simbólica que intervém no real" (p. 44).

Sob essa perspectiva teórica, o estudo buscou focalizar charges veiculadas na internet que envolvem assuntos da matemática, buscando interpretar o discurso irônico, humorístico e o sentido do enunciado.

Nas charges a ironia será analisada como um processo discursivo, qual pode ser observada em diferentes manifestações de linguagem. Para Brait (1996), o destino interpretativo no discurso irônico, atua segundo uma estratégia que inclui previsões do movimento do outro. Ou seja, o discurso irônico provoca um jogo entre o que o enunciado diz e o que o enunciador ${ }^{5}$ quer dizer, e conta com o envolvimento do leitor ou enunciatário.

Nesse sentido, Brait (1996) afirma:

"O produtor de ironia encontra formas de chamar a atenção do enunciatário para o discurso, e através desse procedimento, contar com sua adesão. Sem isso a ironia não se realiza. O conteúdo, portanto, estará subjetivamente assinalado por valores atribuídos pelo enunciador, mas apresentados de forma a exigir a participação do enunciatário" (p.129).

No discurso irônico o objetivo do enunciador é desmascarar valores que se colocam como únicos e verdadeiros, assim como buscar denunciar problemas e acontecimentos culturais, sociais e históricos. De modo que em muitas vezes se trata de um problema ou assunto do coletivo.

Nesse enfoque Brait (1996, , menciona que:

"O processo irônico fundamenta-se na lógica dos contrários na tensão entre o literal e o figurado e numa relação muito especial entre o enunciador e seu objeto de ironia, e entre o enunciador e o enunciatário. A ironia requer de seu produtor uma familiaridade muito grande com os elementos a serem ironizados, o que de imediato torna isomorfa a cisão constitutiva do seu sujeito, do seu produtor. Por outro lado, também o enunciatário espelha a cisão, na medida em que capta a sinalização emitida pelo discurso e, através dela, aciona sua competência discursiva, ou como parceiro de um ponto de vista do enunciador" (p. 129).

Nessa perspectiva se constata que a natureza da ironia é a ambiguidade, visto que pode apresentar diferentes sentidos, tornando a interpretação impossível de ser resolvida, e gerando muita das vezes o humor. É no discurso humorístico que o enunciante quando faz a crítica, o faz apropriando-se de vozes que o antecedem, isto é, "se é verdade que existem piadas que criticam não se deve esquecer que elas, de fato, reproduzem, e só indiretamente, discursos que já circulam de alguma forma." (Possenti, 1998, p.49).

Portanto, o texto produzido com ironia ou humor são textos que podem incluir modos de enunciação, preconceitos, estereótipos sociais, proibições e controle de temas, pois como afirma Possenti (1998):

"O que caracteriza o humor é muito provavelmente o fato de que ele permite dizer alguma coisa mais ou menos proibida, mas não

\footnotetext{
${ }^{5}$ Segundo Maingueneau (1997, p. 77) os “enunciadores” são seres cujas vozes estão presentes na enunciação sem que lhes possa, entretanto, atribuir palavras precisas; efetivamente, eles não falam, mas a enunciação permite expressar seu ponto de vista. Ou seja, o "locutor" pode pôr em cena, em seu próprio enunciado, posições diversas da sua, instaurando a polifonia.
} 
necessariamente crítica, no sentido corrente, isto é, revolucionária, contrária aos costumes arraigados e prejudiciais. O humor pode ser extremamente reacionário, quando é uma forma de manifestação de um discurso veiculador de preconceitos" (p. 49).

Assim também, a produção de charges são exemplos em que se podem encontrar situações de discursos irônicos ou de humor, onde os chargistas buscam brincar, denunciar, chamar a atenção e até criticar as mais diferentes situações.

\section{Gênero charge}

O gênero charge tem como característica fundamental a crítica social, isso exige que o fato abordado na charge apresente informações compartilhadas e de memórias coletivas, viabilizando a compreensão. Segundo Lima (2012), "a charge utiliza-se de um humor circunstancial que exige conhecimentos de suas condições de produção" (p.30). Assim os textos humorísticos são produzidos em torno de acontecimentos reais e sua interpretação depende de um saber bastante preciso a tais acontecimentos.

Se os sujeitos envolvidos no processo de leitura não compartilharem da informação que está sendo abordado pelo chargista, o efeito de humor "cai por terra", como afirma Possenti (2010), ao tentar explicar uma charge que para ele "é completamente incompreensível se não se fornece um conjunto de informações" (p. 145). Assim ao se analisar uma charge, a leitura deve ser profunda, visto que além dos fatos da língua temos os fatos ideológicos históricos, sociais e culturais. Na charge se mesclam todos os elementos que tentam levar ao humor.

Nesse sentido, conforme Lima (2012), a charge recorre sempre à memória social, pois está ligada a fatos históricos. Em razão disso, a autora conceitua a memória como circunstancial, pois se perde quando a leitura se distancia no tempo do acontecimento representado. O que ocorre é que "a charge nos remete a uma memória compartilhada por um certo grupo social e essa memória social nem sempre resiste ao tempo" (p. 35). Portanto a charge trata de representar o acontecimento já memorizado, e que apresente certa importância na história desses grupos sociais. Portanto, quando o leitor encontra-se afastado do fato representado a construção de sentido da charge será mais difícil.

Neste estudo, ao se pesquisar e analisar as charges que abordam assuntos relacionados à matemática, se constatou que as mesmas buscam em geral expressar a dificuldade da disciplina em relação, à abstração aos símbolos as equações as fórmulas e a falta de compreensão quanto à aplicabilidade de conteúdos específicos em situações práticas do dia a dia.

Estas dificuldades da matemática aqui citadas encontram-se presentes nos textos das charges que compõem a pesquisa. De modo que, a posição em relação ao conhecimento da matemática por muitas pessoas é possível de identificação nas situações expressas e enunciadas pelo chargista. Qual explora em seus textos a raiva, a gozação, a falta de compreensão e interpretação que certas pessoas enfrentam ao estudar matemática. $\mathrm{O}$ texto dessas charges busca explorar o gênero do humor relacionando números, fórmulas e problemas.

A matemática por ser uma ciência formal e abstrata constituída por uma linguagem de números e símbolos gera a necessidade de um maior esforço para a compreensão e domínio de seu conteúdo. Isso tem criado ao longo dos anos certo desprezo pela disciplina, gerando um estigma de que a matemática é uma disciplina difícil ou impossível de se entender. Isso é relatado por estudantes e pessoas que por diversos motivos podem apresentar dificuldade em aprender matemática. Entretanto, é necessário destacar que isso não é realidade para todos, porém o discurso histórico de que a matemática é uma disciplina para poucos, tem gerado a baixa autoestima de 
estudantes e a ideia de incapacidade quando o conteúdo exige um raciocínio lógico mais profundo.

Assim, no processo de ensino aprendizagem muitas vezes o estudante não consegue relacionar os conteúdos matemáticos ensinados a ele com sua vivência, suas atividades fora da escola, de modo que, ao não compreender o conceito do assunto estudado, o conhecimento se torna muito mais abstrato e sem sentido e isso inviabiliza a construção do conhecimento matemático.

Podemos constatar nas aulas de matemática que, a facilidade encontrada no cotidiano por estudantes na execução de certos processos matemáticos como o cálculo mental, por exemplo, não se refletem da mesma maneira no ambiente escolar quando é solicitado a estes estudantes que façam o registro ou a sistematização desse raciocínio.

As diferentes formas de representação dos objetos matemáticos e a associação entre eles, bem como o formalismo matemático, a organização e representação dos conceitos e saberes tem-se mostrado distante e desconhecido para a maioria dos estudantes. Com este tipo de situação o estudante passa a memorizar os conteúdos para conseguir a nota que lhe é necessário obter na prova, levando-o a sua aprovação. Contudo, este estudante se encontra limitado a não manifestar capacidade de mobilizar diferentes registros de representação do objeto matemático, a fim de alcançar um maior desenvolvimento cognitivo. Por consequência, isso desencadeia um processo de limitação no desenvolvimento e autonomia do raciocínio matemático.

Alguns autores tratam da importância de se utilizar de diferentes representações semióticas na compreensão da matemática, a fim de possibilitar o desenvolvimento geral das capacidades de raciocínio, de análise e de visualização. Entre estes autores destaca-se, Raymond Duval o precursor da teoria das representações semióticas no ensino do conhecimento matemático ${ }^{6}$.

Segundo Duval (2009) a construção do conhecimento matemático envolve a apreensão de pelo menos dois registros de representação, assim, as representações semióticas tornam-se essenciais para a compreensão do saber matemático pelo estudante. Para o autor, aprender matemática requer uma atividade cognitiva diferente daquela requerida em outros domínios de conhecimento. Isso ocorre em função da grande variedade de representações semióticas que são utilizadas no campo da matemática.

Em razão disso "a compreensão em matemática implica na capacidade de mudar de registro. Isso porque não se deve jamais confundir um objeto e sua representação". (Duval, 2003, p.21). Uma vez que na matemática os objetos são inacessíveis, perceptivamente ou instrumentalmente, assim o acesso aos mesmos se dá necessariamente por representações semióticas.

Então, a falta de conhecimento e capacidade de manipulação dos diferentes registros de representação dos objetos matemáticos, dificulta a aquisição do saber e aumenta o nível de abstração dos conteúdos. Este tipo de situação tem gerado ao longo da história frases como: "A Matemática é muito difícil", "Matemática é chata", "eu odeio esta matéria". Frases estas que se constituem em discursos utilizados por muitas pessoas na sociedade. Chegando ao ponto da matemática ser concebida socialmente como a disciplina que conduz ao insucesso. Assim, o discurso passa a ser histórico, ressaltando através das falas já pré-construídas que os conteúdos de matemática são difíceis de aprender.

Esse discurso negativo referente à matemática que se faz presente nas opiniões dos estudantes ou mesmo no discurso de pessoas que não mais se encontram na escola

\footnotetext{
${ }^{6}$ Filósofo e psicólogo de formação, autor de muitos trabalhos envolvendo a psicologia cognitiva e o papel dos registros de representação semiótica para o ensino aprendizagem do conhecimento matemático.
} 
revelam sentidos repetidos de outras vozes, como ecos de ressonância de dizeres que já foram ditos e analisados nas vozes: dos pais, dos amigos, do professor, da mídia e da própria sociedade.

De acordo com Pêcheux, o sujeito que apresenta no interdiscurso manifestações do que já foi dito, se trata do sujeito assujeitado que se manifesta conforme sua formação social e com sua historicidade. Este sujeito interpretante que lida com sentidos construídos socialmente, mas que dá sentidos seus, é inscrito na psicanálise, quando se depara com o "outro" na sua fala.

Para tanto, Ferreira (2004) enfatiza que:

"A análise do discurso se define, desde sua concepção inicial, como uma disciplina que se constitui numa zona de interface, na fronteira entre o sentido e o não-sentido; entre o possível e o impossível; entre a completude e a incompletude. A psicanálise, por sua vez, se situa também na fronteira entre o consciente e o inconsciente; entre a lembrança e o esquecimento, entre o dito e o não-dito. As linhas demarcatórias entre as duas áreas assinalam o lugar do fim e também do início; ao mesmo tempo que fecham a fronteira dos respectivos territórios, apontam para um começo, para uma continuidade. Desse modo, início e fim de cada lado se confundem, se imbricam, se enlaçam" (p. 39).

Com base nestes teóricos, podemos perceber que o discurso que fala da dificuldade da matemática, se trata de um discurso pré-construído, que está sendo repetido pelos estudantes pela sociedade e reconhecido nas marcas linguísticas das suas formulações discursivas.

\section{Método}

O estudo referente ao gênero discursivo aplicado em charges que abordam temas do campo matemático apresentou por método a pesquisa bibliográfica, com uma abordagem qualitativa. Para tanto se buscou na literatura, diferentes autores que discutem a teoria da Análise do Discurso, assim como os tipos de gênero presentes na elaboração de uma charge.

A partir das leituras se realizou uma compilação crítica dos teóricos que tratam da Análise do Discurso, com o objetivo de estudar qual o papel do diálogo no discurso. Posteriormente, foi realizada uma coleta de charges publicadas em sites que envolvessem assuntos matemáticos, com o intuito de analisar o discurso presente nesse tipo de gênero que transita de forma harmoniosa entre as linguagens verbal e não verbal.

Cabe ressaltar que, neste estudo, não se teve a intenção de discutir a necessidade da aplicação de metodologias para o ensino da matemática, bem como a atuação docente e o domínio deste sobre os conteúdos conceituais os conteúdos atitudinais e procedimentais no ensino da matemática. Mas sim, o estudo buscou analisar o discurso de linguagem presente em charges que abordam temas matemáticos.

\section{Resultado e discussões}

Como resultado da pesquisa se apresenta nesta secção, as charges que foram selecionadas na internet para compor a amostra deste estudo, seguidas da análise do texto apresentado pelo chargista. Está análise ocorre à luz da teoria da $\mathrm{AD}$ qual fundamenta o estudo.

A primeira charge analisada apresenta um texto composto por imagens de números e símbolos matemáticos assim como um texto descrito em linguagem natural. 


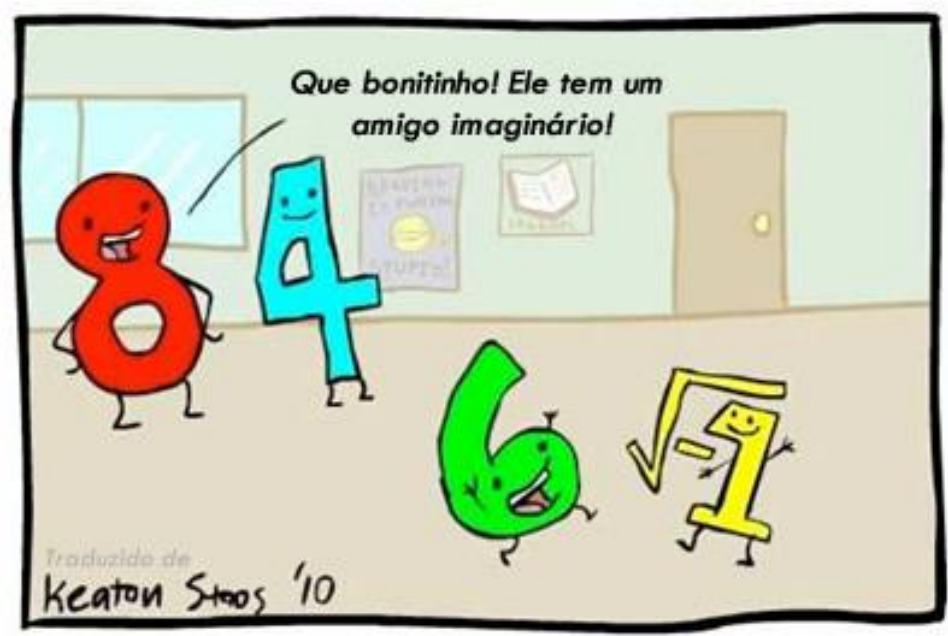

Figura 2. Sem título

Note: Fonte: Disponível em < http://www.somatematica.com.br/piadas.php> Acesso em 20 de dez. 2016.

Nesta charge verificamos a necessidade do leitor compreender determinados conceitos matemáticos referentes ao campo numérico dos números naturais, inteiros, racionais, irracionais e imaginários. Somente a partir deste conhecimento pré-construído o leitor conseguirá interpretar a relação do texto natural com o texto das imagens, entendendo o humor que o chargista buscou estimular, ao trabalhar os números e o conceito de amigo. Caso o leitor desconheça o que é um número imaginário, não saberia então que $\sqrt{-1}$ é um elemento que pertence ao campo dos números imaginários.

Pode-se supor, como uma leitura possível, que a intenção do chargista, além de trabalhar o humor, é buscar mostrar que para fazer a interpretação o leitor necessita reconhecer os símbolos e conceitos matemáticos, vozes históricas já pré-construídas.

A segunda charge analisada, expressa humor e crítica, por parte do chargista ao abordar uma relação matemática associada a uma situação social relacionada ao governo. A ideia aqui pode ser a de levar o leitor a perceber o descaso do governo com as contas públicas, pois, ao analisar o resultado dos cálculos na charge, apresentando valores superiores ao resultado correto, pode-se comparar a situações em que o governo busca superfaturar as contas, ou seja, aplicar valores muito mais altos em compras, construções ou outras atividades desenvolvidas do que realmente seria o custo verdadeiro. Deste modo, busca chamar a atenção de como o governo pode modificar os resultados conforme lhe convém. Assim, na fala do personagem, ao responder à indagação sobre os cálculos simples, há uma contradição, feita propositalmente pelo cartunista para criticar a atual política brasileira. E isso, na resposta do personagem, produz também o efeito de ironia.

Ou a leitura desta charge pode levar a chamar a atenção para a ideologia da corrupção, da manipulação das informações conforme convenha ao sujeito que as promove. Além disso, mostrar como ações desenvolvidas de modo errado são justificadas por outros erros, ou comparações de atuação.

Com esta crítica irônica o chargista se permite chamar a atenção para diferentes interpretações, diferentes sentidos. Aborda a matemática para ironizar uma situação politica e ao mesmo tempo despertar a atenção do público leitor para os problemas do governo. 


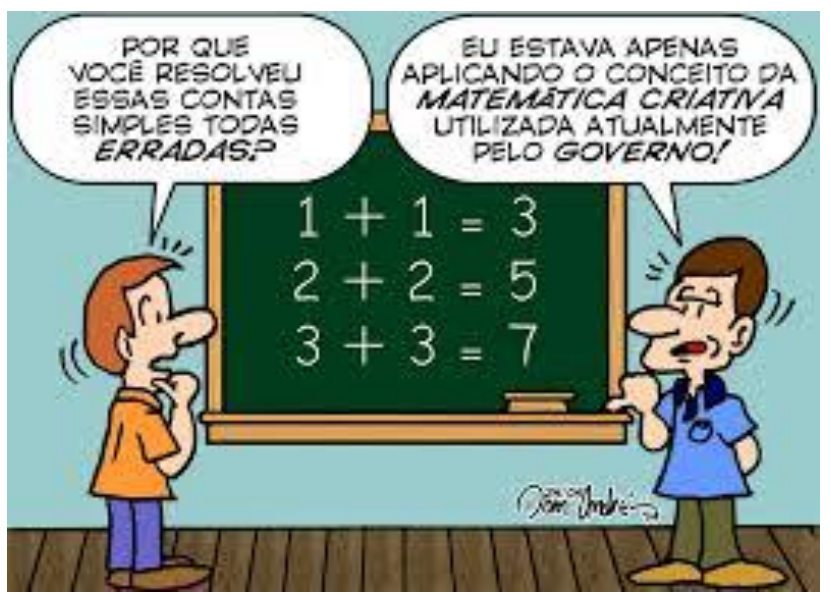

Figura 3. Sem título

Note: Fonte: Disponível em < http://domandreonline.blogspot.com.br/2014/05/charge-da-semana29052014-matematica.html> Acesso em 21 de dez. 2016.

Portanto, para compreender a charge o leitor não deve apenas relaciona-la aos cálculos de matemática, mas a real situação do seu contexto histórico social e politico.

A terceira charge apresenta um diálogo referente à importância da matemática para situações simples do cotidiano.
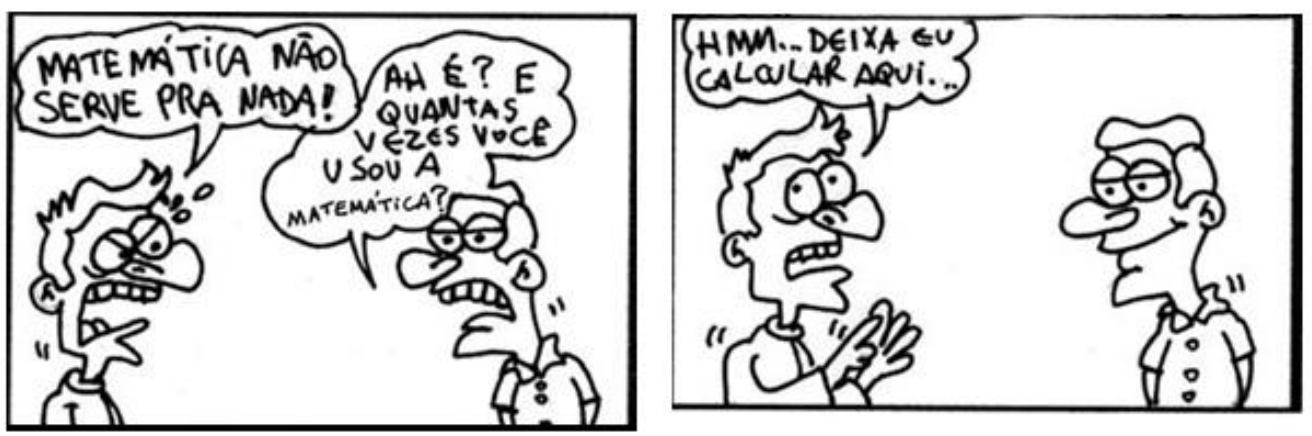

Figura 4. Sem título

Note: Fonte: Disponível em < http://clickgratis.blog.br/integralgrupo10/591125/charges.html> Acesso em 21 de dez. 2016.

Encontramos nesta charge o discurso de que a matemática é uma disciplina que não serve pra nada na vida. Interpretações como essa podem ser expressas por estudantes ou pessoas que não conseguem relacionar o saber matemático com situações práticas vividas no seu dia a dia. A ideologia aqui presente é que, por ser muito abstrata e formal constituída por símbolos a matemática não serve para resolver problemas práticos, essa ideia só pode ser emitida por quem não consegue abstrair o conceito matemático.

O chargista busca provocar essa reflexão fazendo um personagem emitir uma pergunta simples ao outro, mostrando ao leitor que mesmo em coisas simples e que inicialmente não parecem envolver conteúdos matemáticos, visto que o enunciado não fazia menção a números, expressões algébricas ou fórmulas aritméticas, consistindo apenas em uma declaração gratuita de valor existindo a necessidade de utilizar-se da matemática para responder a indagação apresentada. Ressalta-se que a constituição do texto também apresenta sentido de humor e ironia.

$\mathrm{Na}$ quarta charge o texto apresenta um sentido de humor, quando o chargista descreve a fala do personagem estudante ao falar para a professora, "Ei, ei! Mas 
devagarinho! A senhora ontem disse que x era igual a 2!”. A situação expressa nesta charge busca discutir como a representação simbólica na matemática representa dificuldade aos estudantes. O valor ideológico presentado é que as representações algébricas são desprovidas de significado e não fazem relação com a realidade, o que provoca dificuldade de compreensão. Também se percebe a ironia, da situação em função de que a matemática deveria trabalhar apenas números e, portanto, não se utilizar das letras. Fica mostrado, também como os conteúdos algébricos representam um alto grau de dificuldade para os estudantes. A situação aqui remete a necessidade da importância do uso dos registros de representação semiótica, a fim de auxiliar os estudantes na interpretação e aplicação da álgebra.

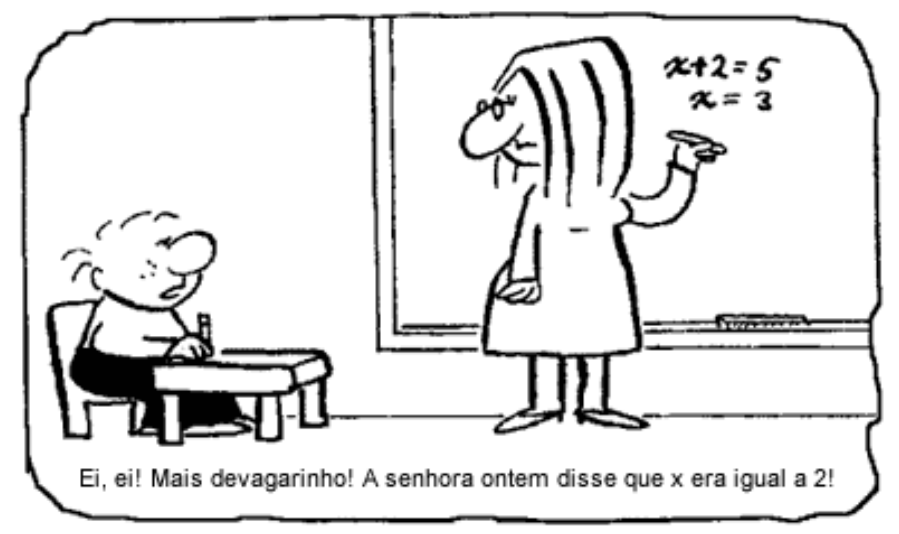

Figura 5. Sem título

Note: Fonte: Disponível em <http://matematica-significativa.blogspot.com.br/2012/02/chargesengracadas.html> Acesso em 20 de dez. 2016.

$\mathrm{Na}$ charge cinco o chargista indicia explorar o humor e também chamar a atenção do leitor, para a importância dos recursos tecnológicos para a atualidade. Um dos sentidos que podemos explorar na charge é o de que, certos cálculos que antigamente demandavam muito tempo e exigiam vários procedimentos matemáticos, atualmente podem ser solucionados com mais rapidez e precisão, em razão da presença dos recursos tecnológicos.

Entretanto, para isso é necessário que o professor esteja apto a fazer o uso dessas novas tecnologias, além do que os estudantes tem buscado cada vez mais fazer o uso de métodos que facilitem o seu trabalho e ocupando menos tempo. Todavia a charge pode também apresentar outro sentido como o de que, os estudantes estão apresentando maiores dificuldades para a resolução de situações simples, o que mostra um despreparo para a sua formação. 


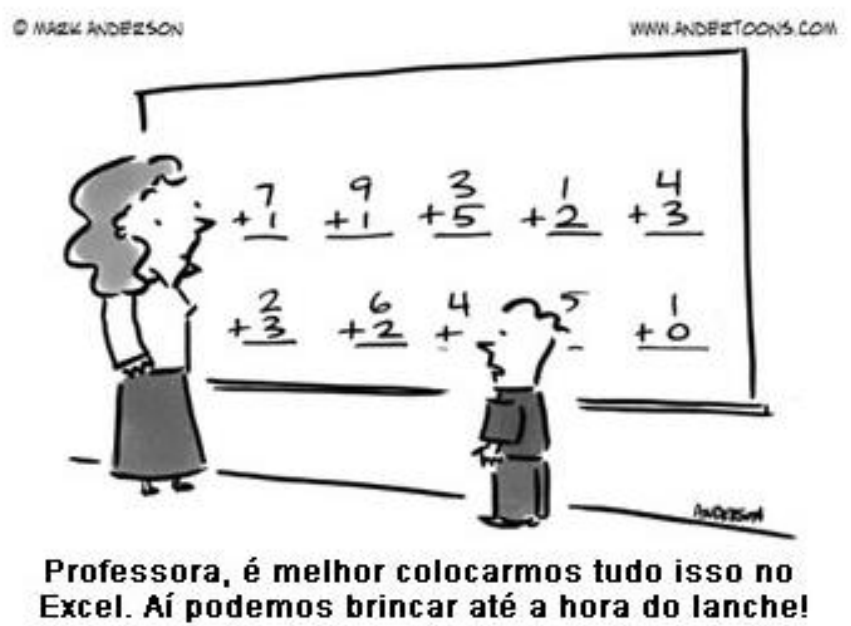

Figura 6. Sem título

Note: Fonte: Disponível em < http://www.somatematica.com.br/piadas.php> Acesso em 20 de dez. 2016.

A charge seis explora e descreve um dos momentos da aula de matemática. $\mathrm{O}$ conteúdo matemático está sendo abordado pelo chargista por meio da língua natural. Caso o leitor compreenda do que assunto se trata, poderá fazer relações, sabendo que este conceito trata do Teorema de Pitágoras. Além de ser expresso em língua natural, também pode ser apresentado em outros registros de representação como o algébrico e o aritmético.

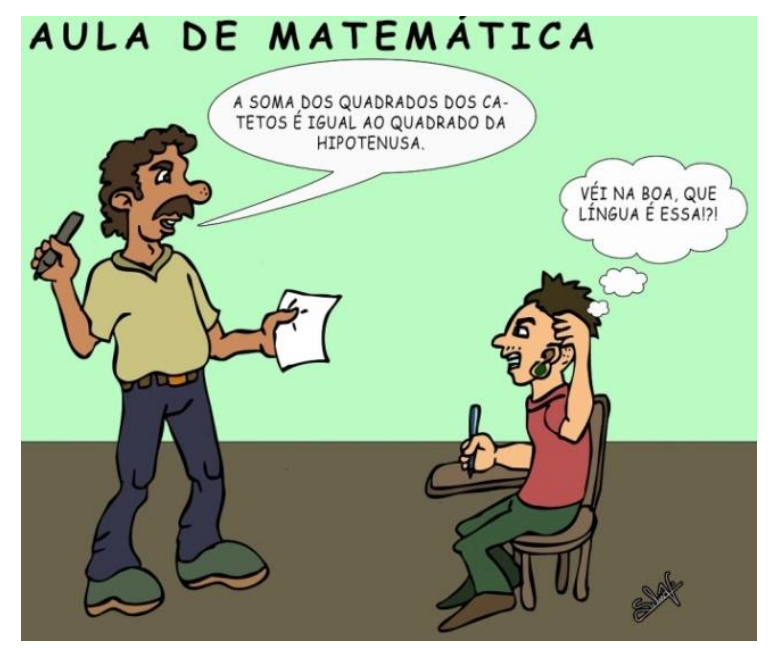

Figura 7. Aula de Matemática

Note: Fonte: Disponível em < http://roraimawebartes.blogspot.com.br/2013/09/charges-roraima-aula-dematematica.html> Acesso em 22 de dez. 2016.

A situação explorada na "Charge 6 - Aula de Matemática" busca enfatizar com humor como a matemática muitas vezes parece ser outra língua para os estudantes, pois na maioria das vezes estes encontram dificuldades de compreender o conceito do objeto em estudo, em razão de não conseguir manipular duas formas de representação para um mesmo objeto. Lembremos que conforme Duval (2003) "a originalidade da atividade matemática está na mobilização simultânea de ao menos dois registros de representação ao mesmo tempo, ou na possibilidade de trocar a todo o momento de registro de representação" (p. 14).

O diálogo criado pelo chargista entre os personagens, também indica a necessidade do professor apresentar domínio do assunto a ser ensinado e para tanto, 
fazer o uso de metodologias de ensino que auxiliem a compreensão do estudante, além do conceito matemático em si.

A charge também apresenta a diferença de linguagem que existe na relação professor e estudante, ou seja, a linguagem científica elaborada seguida pela presença do método, e a linguagem do cotidiano. Deste modo, o chargista busca explanar por meio do humor, o sentido de que estão presentes na sala de aula linguagens diferentes, o que, podem comprometer a interpretação e compreensão do assunto durante a comunicação, ou seja, interação didática.

\section{Conclusões}

O objetivo maior deste estudo foi compilar literaturas que tratam sobre o trabalho com a Análise do Discurso da linha Francesa em gêneros textuais como as charges. Neste estudo o recorte selecionou charges que apresentam textos que envolvem a matemática, buscando então demonstrar que, através do discurso, presente nas charges é possível se caracterizar socialmente, ideologicamente e politicamente os indivíduos. Por meio dos estudos na literatura pesquisada podemos constatar que as charges são um importante registro histórico, pois com suas particularidades como o humor e a ironia, elas criticam e fazem o leitor refletir sobre fatos importantes que podem se constituir como memória coletiva.

Por meio da análise realizada nas charges que compõem este estudo, concluiu-se que o gênero discursivo correspondente não pode ser interpretado longe de seu contexto histórico, político, social e ideológico. Pois os efeitos de sentido no caso da charge e também em outros gêneros circunstanciais variam de acordo com o tempo e com os dados compartilhados entre autor/chargista e leitor.

Os chargistas a fim de atingir o seu propósito se utilizam de diferentes textos e imagens e de manipulações linguísticas. Que serão empregados conforme o discurso e desejo de sentido que o chargista tentará provocar no leitor. Deste modo, a Análise do Discurso propõe que o discurso, nunca será neutro, pois é sempre interpelado pelas vozes da ideologia e construído por outros discursos que se cruzam ou se excluem.

Assim sendo, para a interpretação de charges, e o posicionamento crítico em relação a sua análise se faz necessário um conhecimento preciso dos acontecimentos do contexto de produção que o chargista utilizou durante a criação. Portanto é a partir do conhecimento sobre o assunto abordado e reconhecimento da situação ou momento histórico que o leitor terá sua interpretação constituída.

Observa-se então que, a construção de sentido do gênero charge se dá na junção dos elementos linguísticos, e sócio-histórico-ideológicos bem como na relação de conhecimento do leitor sobre o contexto enunciativo. Portanto, Lima (2012, p. 75) enfatiza que "[...] na charge os signos tendem a ganhar novos sentidos em novos contextos. É pela repetição que o chargista, muitas das vezes, faz-nos rir. É na identificação da mescla de discursos e de textos revitalizados, repetidos, que podemos atribuir novos sentidos e tirar deles o que nos faz rir".

\section{Referências}

Bakhtin, M. (1997). Estética da criação verbal. [tradução feita a partir do francês por Maria Emsantina Galvão G. Pereira revisão da tradução Marina Appenzellerl]. São Paulo Martins: Fontes

Bakhtin, M. M., Jakobson, R., Yaguello, M., Lahud, M., Vieira, Y. F., \& Voloshinov, V. N. (1979). Marxismo e filosofia da linguagem: problemas fundamentais do método sociológico na ciência da linguagem. São Paulo: Hucitec. 
Brait, B. (1996). Ironia em perspectiva polifônica. Campinas: UNICAMP.

Charges matemáticas: Disponível em < http://www.somatematica.com.br/piadas.php> Acesso em 20 de dez. 2016.

Charges matemáticas: Disponível em < http://domandreonline.blogspot.com.br/2014/05/charge-da-semana-29052014matematica.html> Acesso em 21 de dez. 2016.

Charges matemáticas: Disponível em http://clickgratis.blog.br/integralgrupo10/591125/charges.html> Acesso em 21 de dez. 2016.

Charges matemáticas: Disponível em <http://matematicasignificativa.blogspot.com.br/2012/02/charges-engracadas.html > Acesso em 20 de dez. 2016.

Charges matemáticas: Disponível em < http://roraimawebartes.blogspot.com.br/2013/09/charges-roraima-aula-dematematica.html> Acesso em 22 de dez. 2016.

Duval, R. (2009). Semiósis e pensamento humano: registros semióticos e aprendizagens intelectuais. Trad. de Lênio Fernandes Levy e Marisa Roâni Abreu da Silveira. São Paulo: Livraria da Física.

Duval, R., \& Moretti, T. M. T. (2012). Registros de representação semiótica e funcionamento cognitivo do pensamento Registres de représentation sémiotique et fonctionnement cognitif de la pensée. Revemat: Revista Eletrônica de Educação Matemática, 7(2), 266-297

Ferreira, M. C. L. (2004). Análise de Discurso e Psicanálise: uma estranha intimidade. Correio da APPOA, Porto Alegre, (131), 37-52.

Lima, M. D. T. D. (2012). A construção de sentido no gênero charge: O discurso humorístico da crítica social no Brasil nas Eras FHC e Lula.

Maingueneau, D. (1997). Novas tendências em análise do discurso. Pontes.

Marcuschi, L. A. (2008). Produção textual, análise de gêneros e compreensão. São Paulo: Parábola Editorial.

Orlandi, E. P. (1999). Análise de Discurso: princípios e procedimentos. São Paulo: Pontes.

Orlandi, E. P. (2001). Discurso e texto: formulação e circulação dos sentidos. Pontes.

Possenti, S. (1998). Discurso, estilo e subjetividade. São Paulo: M. Fontes.

Possenti, S. (1998). Os humores da língua. Campinas: Mercado de Letras.

Ribeiro, M., Stolzmann, M. R. (1997). A questão da interpretação na análise do discurso e na psicanálise: interseções. Coletâneas do Programa de Pós Graduação em Educação. Porto Alegre, 5(13). 
Data de recebimento: 07/06/2017

Data da revisão: 17/07/2017

Data do aceite: 08/07/2017 
Cataneo, V.I. 